\title{
Oridonin exerts anticancer effect on osteosarcoma by activating PPAR $-\gamma$ and inhibiting Nrf2 pathway
}

Ying Lu', Yang Sun ${ }^{1}$, Jianwei Zhu², Lisha Yu' ${ }^{1}$ Xiubo Jiang ${ }^{1}$, Jie Zhang ${ }^{1}$, Xiaochen Dong ${ }^{2}$, Bo Ma ${ }^{1}$ and Qi Zhang ${ }^{1}$

\begin{abstract}
Osteosarcoma is the most common high-grade human primary malignant bone sarcoma with lower survival in the past decades. Oridonin, a bioactive diterpenoid isolated from Rabdosia rubescens, has been proved to possess potent anti-cancer effects. However, its potential mechanism still remains not fully clear nowadays. In this study, we investigated the anticancer effect of oridonin on human osteosarcoma and illuminated the underlying mechanisms. In vitro, oridonin inhibited the cell viability of various osteosarcoma cells. We demonstrated that oridonin induced mitochondrial-mediated apoptosis by increasing Bax/Bcl-2 ratio, loss of mitochondrial membrane potential (MMP), triggering reactive oxygen species (ROS) generation and activating caspase- 3 and caspase-9 cleavage in MG-63 and HOS cells. Moreover, we found that oridonin triggered ROS by inhibiting NF-E2-related factor 2 (Nrf2) pathway and induced mitochondrial apoptosis via inhibiting nuclear factor-kB (NF-kB) activation by activating Peroxisome Proliferator-Activated Receptor $\gamma$ (PPAR- $\gamma$ ) in MG-63 and HOS cells. We further confirmed the results by PPAR- $\gamma$ inhibitor GW9662, PPAR- $\gamma$ siRNA as well as overexpression of PPAR- $y$ and Nrf2 in vitro. Furthermore, our in vivo study showed that oridonin inhibited tumor growth with high safety via inducing apoptosis through activating PPAR- $\gamma$ and inhibiting Nrf2 activation in xenograft model inoculated HOS tumor. Taken together, oridonin exerted a dramatic proapoptotic effect by activating PPAR- $\gamma$ and inhibiting Nrf2 pathway in vitro and in vivo. Therefore, oridonin may be a promising and effective agent for human osteosarcoma in the future clinical applications.
\end{abstract}

\section{Introduction}

Osteosarcoma is the most common high-grade primary malignant bone tumor and prevailing in children and young adults ${ }^{1}$. The standard therapy for osteosarcoma consists of neoadjuvant chemotherapy, surgical excision and chemotherapy again after resection ${ }^{2}$. Despite the advances in surgical technique, relapse and chemotherapy resistance is still the main challenges for physicians ${ }^{3}$. Over

\footnotetext{
Correspondence: Yang Sun (sunyangsunny@sina.com) or Bo Ma (mabo201012@njtech.edu.cn) or Qi Zhang (zhangqi@njtech.edu.cn) ${ }^{1}$ School of Pharmaceutical Sciences, Nanjing Tech University (NanjingTech), 30 South Puzhu Road, Nanjing 211816, The People's Republic of China ${ }^{2}$ Key Laboratory of Flexible Electronics (KLOFE) \& Institute of Advanced Materials (IAM), Jiangsu National Synergetic Innovation Center for Advanced Materials (SICAM), Nanjing Tech University (NanjingTech), 30 South Puzhu Road, Nanjing 211816, The People's Republic of China

Ying Lu, Yang Sun and Jianwei Zhu contributed equally to this work. Edited by G.M. Fimia
}

the last three decades, the 5-year survival of patients with local osteosarcoma has improved to $60 \%$, but has remained essentially unchanged ${ }^{4}$. Consequently, it is indispensable to develop more effective therapies against osteosarcoma.

Peroxisome Proliferator-Activated Receptor $\gamma$ (PPAR$\gamma$ ), one kind of the nuclear hormone receptor family, plays a key role in carcinogenesis ${ }^{5}$. PPAR- $\gamma$ has been considered as a tumor suppressor in many solid cancers including human breast, prostate, colon, and lung cancer ${ }^{6}$. PPAR- $\gamma$ activation possesses potential anticancer effects both in solid cancer and in leukemia through induction of apoptosis, inhibition of cell proliferation, terminal differentiation $^{6}$. Increasing evidence has demonstrated that PPAR- $\gamma$ activation may be considered as a possible intervention in 


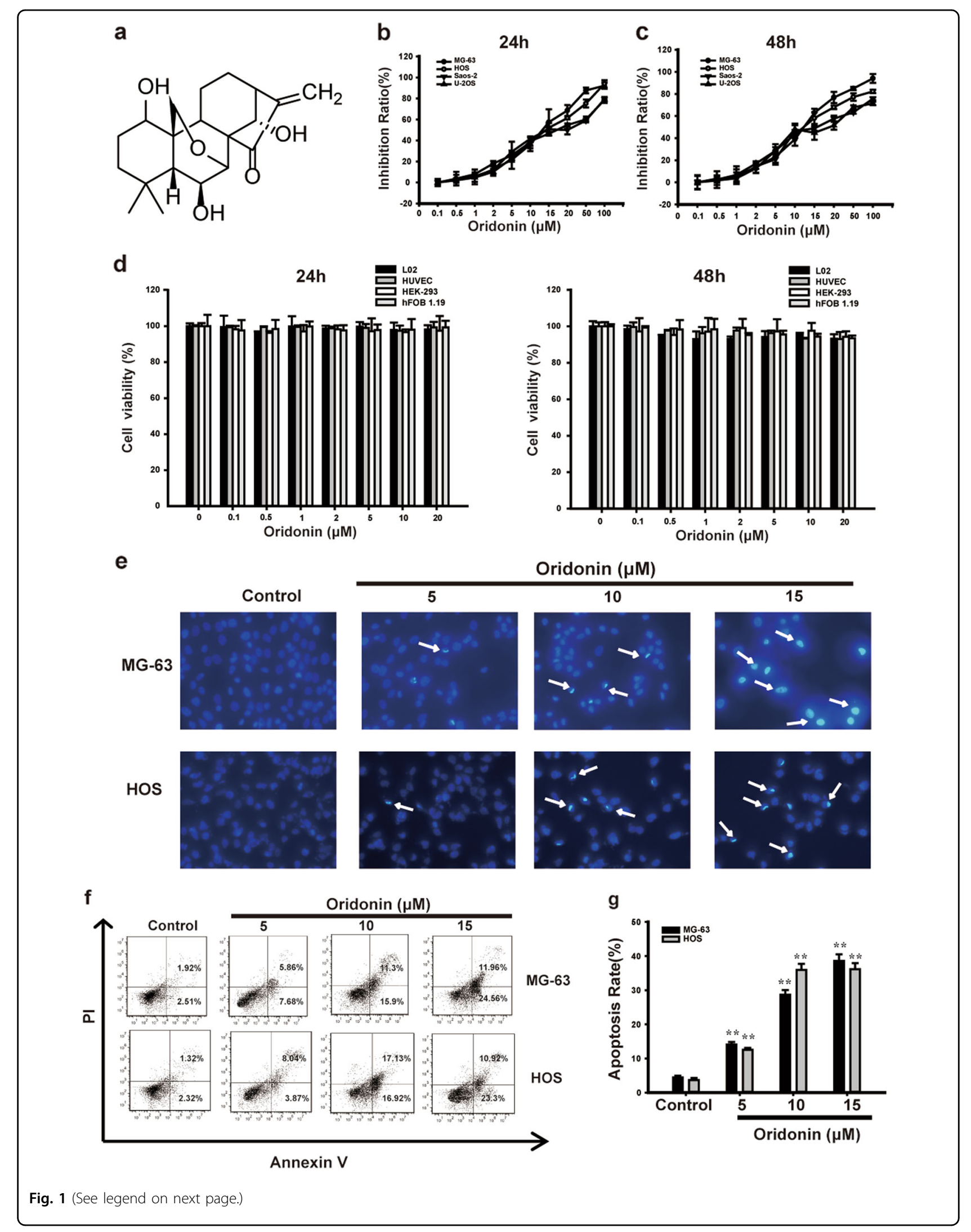


(see figure on previous page)

Fig. 1 Oridonin induced apoptosis in human osteosarcoma cells. a Structure of oridonin $\left(\mathrm{C}_{20} \mathrm{H}_{28} \mathrm{O}_{6}, \mathrm{MW}=364.4327\right)$. $\mathbf{b}$ The effect of oridonin on the cell viability of MG-63, HOS, Saos-2 and U-2OS cells after $24 \mathrm{~h}$ treatment. c The effect of oridonin on the cell viability of MG-63, HOS, Saos-2, and U-2OS cells after $48 \mathrm{~h}$ treatment. d The effect of oridonin on the cell viability of human normal cells L02, HUVEC, HEK-293 and human normal osteogenic cell lines hFOB 1.19 after $24 \mathrm{~h}$ treatment. e After given oridonin $(5,10$, and $15 \mu \mathrm{M})$ for $24 \mathrm{~h}$, the nuclear morphologic changes of MG-63 and HOS cells were observed by fluorescent microscope (400X). Apoptosis bodies and nuclei pyknosis were observed in apoptosis cells. $\mathbf{f}, \mathbf{g}$ The apoptotic rates of cells induced by oridonin in MG-63 and HOS cells detected by Annexin V/PI double-staining assay. The results are representative of at least three independent experiments and shown as mean \pm SD. ${ }^{* *} P<0.01$ compared with control group

osteosarcoma $^{7-11}$. PPAR- $\gamma$ agonists can promote osteoblastic differentiation of osteosarcoma cells ${ }^{12}$ and suppress its proliferation ${ }^{13}$. In addition, activating PPAR- $\gamma$ exerts the anticancer effects through the inhibition of the activation of nuclear factor- $\kappa B(N F-\kappa B)^{14,15}$. NF- $\kappa B$ family is consisted of five related transcription factors regulating gene transcription in various physiological conditions ${ }^{16}$. It is well known that aberrant NF- $\kappa B$ activity is invoved in the cell proliferation, the subversion of apoptosis and cancer development ${ }^{17}$. Overactive NF- $\kappa B$ signaling pathway regulates many carcinogenic genes ${ }^{16}$ and is reported in numerous cancers such as leukemias, breast cancer, prostate cancer, melanoma, lymphomas ${ }^{18}$, especially in osteosarcoma $^{19}$. Notably, a recent study further demonstrated the activation of NF- $\mathrm{kB}$ leads to increase cell proliferation in osteosarcoma and hinder osteoblastic differentiation ${ }^{16}$. Therefore, blockage of NF- $\kappa$ B activation sensitizes osteosarcoma to chemotherapeutic agents ${ }^{19}$.

NF-E2-related factor 2 (Nrf2), a transcription factor that modulates the level of reactive oxygen species (ROS), detoxifying agents and antioxidants ${ }^{20}$. Currently, substantial evidence has suggested that Nrf2 pathway is activated to trigger the expression of antioxidant response element (ARE) target genes, including $\mathrm{NAD}(\mathrm{P}) \mathrm{H}$ :quinone oxidoreductase 1 (NQO1) and heme oxygenase-1 (HO-1), which attenuate cellular oxidative stress ${ }^{21,22}$. It has been clearly documented that Nrf2 plays a crucial role in the progression, invasion, and metastasis of various cancers ${ }^{23}$. The elevated expression of Nrf2 has been found in head and neck ${ }^{24}$, gall bladder ${ }^{25}$ and lung cancer ${ }^{26}$. Documents showed that the accumulation of Nrf2 in the nuclei is closely related to bone metastasis of patients with osteosarcoma, indicating that activation of Nrf2 is vital for the development and progression of osteosarcoma ${ }^{27}$. However, the significance of Nrf2 in osteosarcoma tissue need to be further studied.

Oridonin, a diterpenoid isolated from medicinal herb Rabdosia rubescens, has been proved to possess potent antitumor effect on various cancers, such as colon cancer cells ${ }^{28}$, lymphoma cells ${ }^{29}$, breast cancer cells ${ }^{30}$ and leukemia cells ${ }^{31}$. It has been documented that oridonin may induce apoptosis in numerous cancers ${ }^{32,33}$. In addition, JDA-202 and adenanthin, which possess the same active site structure with oridonin, has been proved to target peroxiredoxins to exert their antitumor activity ${ }^{34,35}$.
Moreover, there is an enormous work investigating the mechanism of the antitumor effect of oridonin ${ }^{36}$. However, its potential molecular mechanism of the antitumor effect is still not fully clear, especially on osteosarcoma. Therefore, we explored the anticancer effect of oridonin on human osteosarcoma and the underlying mechanisms. We demonstrated that oridonin exerted a dramatic proapoptotic effect by activating PPAR $-\gamma$ and inhibiting Nrf2 pathway in vitro and in vivo.

\section{Results}

Oridonin induced apoptosis in human osteosarcoma cells

The chemical structure of oridonin was shown in Fig. 1a. To evaluate the inhibitory effect of oridonin on cell viability of human osteosarcoma cell lines including MG-63, HOS, Saos-2 and U-2OS cells, we performed MTT test at different concentrations after 24 or $48 \mathrm{~h}$ treatment of oridonin. After $24 \mathrm{~h}$ of treatment, the IC50 (the concentration of drug inhibiting $50 \%$ of cells) values of MG-63, HOS, Saos-2 and U-2OS cells were 12.29 \pm $1.02,13.22 \pm 0.86,19.72 \pm 0.75,19.56 \pm 0.47 \mu \mathrm{M}$, respectively (Fig. 1b). After $48 \mathrm{~h}$ of treatment, the IC50 values of MG-63, HOS, Saos-2, and U-2OS cells were $10.88 \pm 0.72$, $11.91 \pm 0.58,17.32 \pm 0.42,17.71 \pm 0.62 \mu \mathrm{M}$, respectively (Fig. 1c). MG-63 and HOS cell lines were more susceptive to oridonin, thus we used these two cell lines with 5,10 , and $15 \mu \mathrm{M}$ of oridonin treatment for $24 \mathrm{~h}$ in the following experiments. We used several human cancer cell lines to compare the activity of oridonin to osteosarcoma. MTT assays showed that after oridonin treatment for $24 \mathrm{~h}$, the IC50 (the concentration of drug inhibiting 50\% of cells) values of A549, BXPC-3, HCT-116, Hela, SKOV-3, AGS, K562 cells were $56.47 \pm 0.17,63.91 \pm 0.11,19.18 \pm 0.27$, $65.5 \pm 0.16,23.56 \pm 0.27,23.36 \pm 0.24,21.78 \pm 0.25 \mu \mathrm{M}$, respectively (Supplementary Figs. 1a, b). In addition, we chose cisplatin as the positive compound to compare the inhibitory effect of oridonin on osteosarcoma. We found that after treatment of cisplatin for $24 \mathrm{~h}$, the IC50 values of MG-63, HOS, Saos-2 and U-2OS cells were $24.26 \pm$ $0.29,30.81 \pm 0.21,30.02 \pm 0.22,26.61 \pm 0.25 \mu \mathrm{M}$ respectively. After $48 \mathrm{~h}$ of treatment, the IC50 values of MG-63, HOS, Saos- 2 and U-2OS cells were $21.1 \pm 0.28,29.52 \pm$ $0.22,27.6 \pm 0.26,23.82 \pm 0.24 \mu \mathrm{M}$ respectively (Supplementary Figs. 2a, b). These results showed that osteosarcoma was more susceptive to oridonin. Moreover, we 
used human normal cells L02, HUVEC, HEK-293 and human normal osteogenic cell lines hFOB 1.19 to evaluate the safety of the concentrations of oridonin we chose in vitro. MTT assays showed that there were no significant effects on cell viability of L02, HUVEC, HEK-293 and hFOB 1.19 cells after treatment with the same concentration of oridonin (Fig. 1d). These data suggested that oridonin had a selectively inhibitory effect on osteosarcoma cells but not on normal cells.

We used DAPI staining assay to test if oridonin induced apoptosis in MG-63 and HOS cells. The result showed that the control cells were in round shapes, whereas cells treated with oridonin had apoptotic chromatin condensation and DNA fragmentation in a dosedependent manner (Fig. 1e). We confirmed the proapoptotic effect of oridonin by Annexin V/PI staining assay. As shown in Figs. 1f, g, the number of apoptotic cells was remarkably increased by oridonin in a dosedependent manner compared with control group. The quantitative analysis for the percentage of apoptotic cells showed that oridonin significantly induced apoptosis in MG-63 and HOS cells. Our findings demonstrated that oridonin induced typical apoptosis in human osteosarcoma cells.

\section{Oridonin induced mitochondrial apoptosis in MG-63 and HOS cells}

To illustrate the mechanism of oridonin-induced apoptosis, mitochondrial membrane potential (MMP) was detected by flow cytometry. We found that MMP sharply decreased following oridonin treatment in a dose-dependent manner (Figs. 2a, b). Moreover, we detected the levels of the apoptosis related proteins such as Bcl-2, Bax, Cleaved caspase- 9 , Cleaved caspase- 3 by Western Blot. After treatment with oridonin for $24 \mathrm{~h}$, the pro-apoptotic protein Bax expression was increased while the anti-apoptotic protein $\mathrm{Bcl}-2$ expression was decreased in a dose-dependent manner (Fig. 2c). The ratio of $\mathrm{Bax} / \mathrm{Bcl}-2$ was dose-dependently increased by oridonin (Fig. 2d). The mRNA levels of Bcl-2 and Bax was also regulated by oridonin accordingly (Figs. 2e, f). Besides, Caspase-3 and Caspase-9 cleavage were remarkably activated after oridonin treatment (Fig. 2c). The ratios of Cleaved caspase-9/Pro-caspase- 9 and Cleaved caspase-3/Pro-caspase-3 were significantly increased after oridonin treatment (Fig. 2d). We next determined the activities of Caspase- 9 and Caspase- 3 in MG-63 and HOS cells after oridonin treatment. We found that oridonin increased the activities of Caspase-9 and Caspase-3 (Figs. 2g, h).

The oxidative stress is an important factor leading to mitochondrial dysfunction, thus causes excessive generation of ROS and the imbalance of oxidation system and antioxidation system $^{37}$. Therefore, we examined the effect of oridonin on ROS generation in MG-63 and HOS cells. Our results showed that oridonin increased the generation of ROS in MG-63 and HOS cells (Figs. 2i, j). The results demonstrated that oridonin induced apoptosis by triggering excessive generation of ROS. Taken together, all these findings indicated that oridonin induced mitochondrial apoptosis in MG-63 and HOS cells.

\section{Oridonin inhibited NF-KB signaling pathway via activating PPAR- $y$ in vitro}

NF- $\mathrm{KB}$ signaling pathway is extremely activated in human osteosarcoma ${ }^{17}$. The activation of PPAR- $\gamma$ exerts the anticancer effects through inhibition of NF- $\mathrm{KB}^{14,15}$. To further illuminate the detailed mechanisms, we examined whether oridonin could affect PPAR- $\gamma$ expression and NF- $\mathrm{KB}$ activation. As shown in Figs. 3a, b, oridonin significantly increased the protein expression of PPAR- $\gamma$ in MG-63 and HOS cells in a dose-depended manner. The levels of NF- $\mathrm{KB}$ in cytoplasm and nucleus were monitored to validate whether oridonin could inhibit NF- $\mathrm{KB}$ activation in MG-63 and HOS cells. Oridonin significantly increased NF- $\kappa B$ in the cytoplasm and decreased NF- $\kappa B$ inside the nucleus (Figs. 3a, b). The inhibitory effect of oridonin on nuclear translocation of NF- $\mathrm{KB}$ was confirmed by immunofluorescence staining (Fig. 3c). Oridonin also inhibited the protein expression of phosphorylation of NF-kB p65 (Fig. 3d).

To determine whether oridonin inhibited NF- $\mathrm{KB}$ activation by activating PPAR- $\gamma$, MG-63 and HOS cells were pretreated with GW9662, a well-known inhibitor of PPAR- $\gamma$. The inhibitory effect of oridonin on activation and nuclear translocation of NF- $\mathrm{\kappa B}$ was reversed by the presence of GW9662 (Figs. 3e-g). These findings supported the fact that oridonin inhibited activation of NF$\kappa B$ by activating PPAR- $\gamma$ in MG-63 and HOS cells. We further detected the effects of oridonin on the protein expression of Bax, Bcl-2, Cleaved caspase- 9 and Cleaved caspase-3 in the presence of GW9662. After pretreatment with GW9662, the effects of oridonin on the protein expression of apoptosis related proteins was obviously reversed (Figs. 3h, i). The flow cytometry analysis demonstrated that the percentage of early and late apoptotic cells of oridonin group was withdrawn by oridonin (Fig. 3j). Moreover, we silenced PPAR- $\gamma$ with PPAR- $\gamma$ siRNA in MG-63 and HOS cells. Remarkably, the inhibitory effect of oridonin on the nuclear translocation and activation of NF- $\kappa B$ was reversed by PPAR- $\gamma$ siRNA transfection (Supplementary Fig. 3a-c). Furthermore, we overexpressed PPAR- $\gamma$ by PPAR- $\gamma$ plasmid in MG-63 and HOS cells. Both the presence of oridonin and PPAR- $\gamma$ plasmid inhibited the nuclear translocation and activation of NF- $\mathrm{KB}$ (Supplementary Fig. 3d-f). These findings suggested that oridonin inhibited 
a

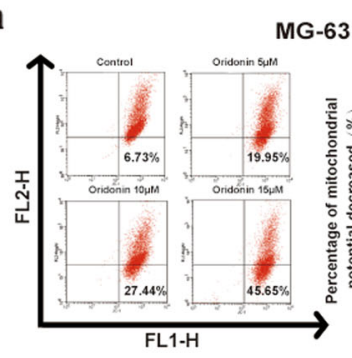

MG-63

C

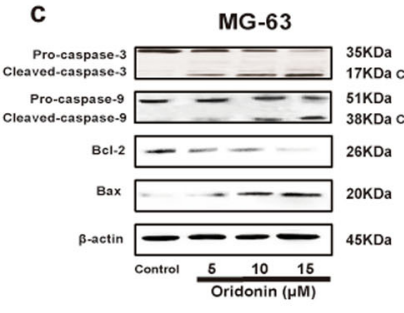

e

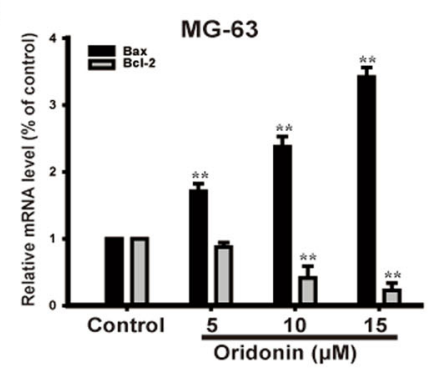

h

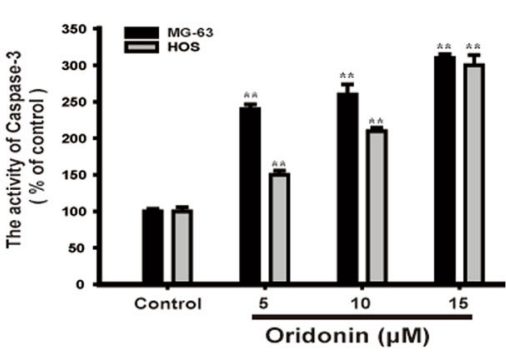

j

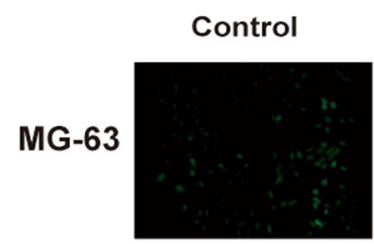

HOS

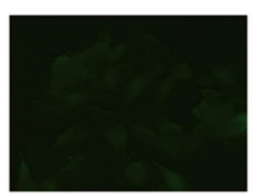

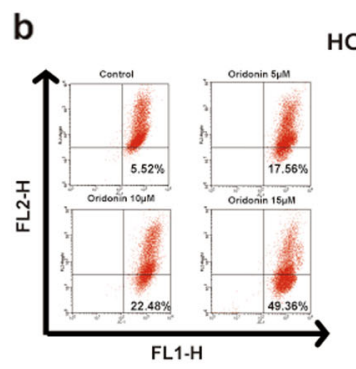

HOS
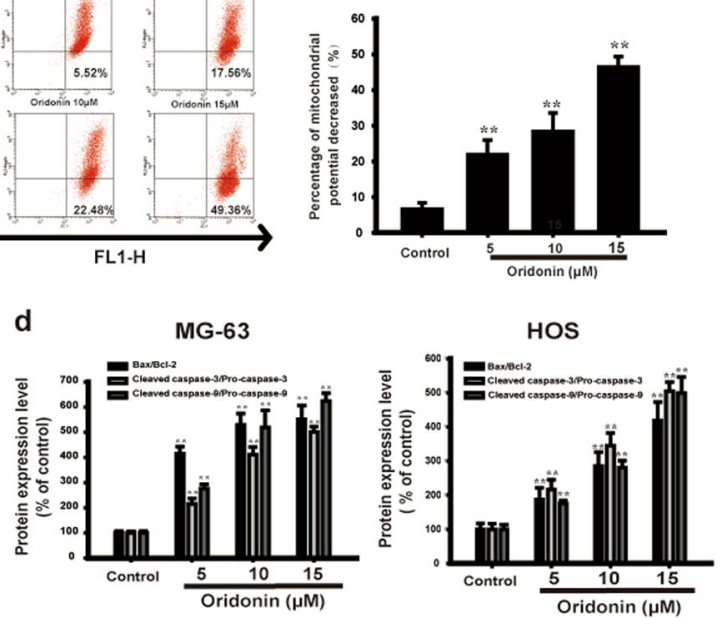

g
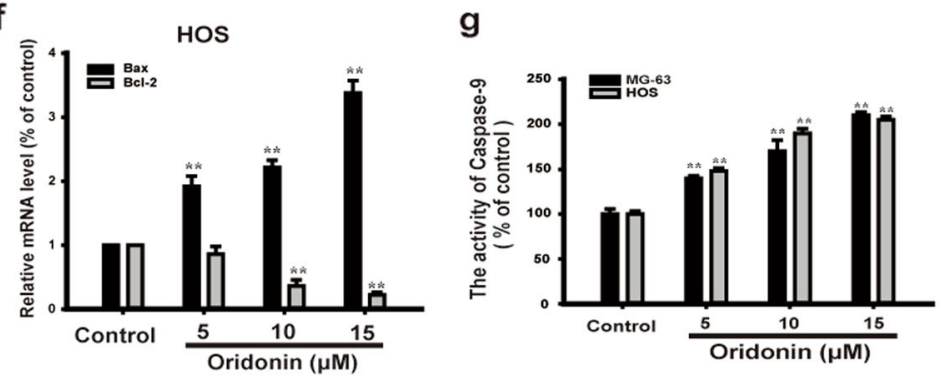

i
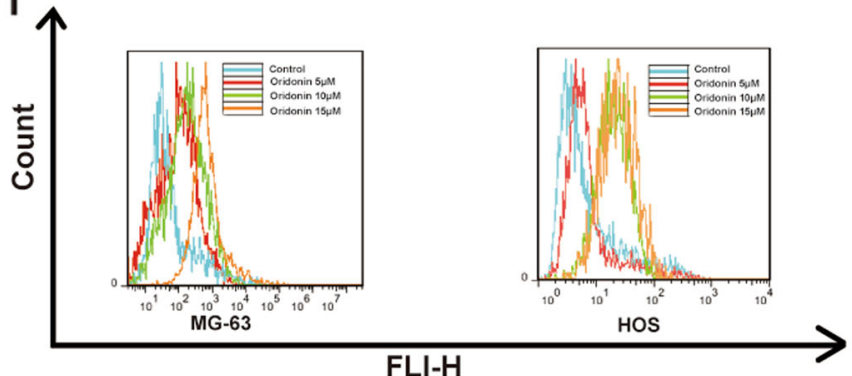

FLI-H

Oridonin $(\mu \mathrm{M})$
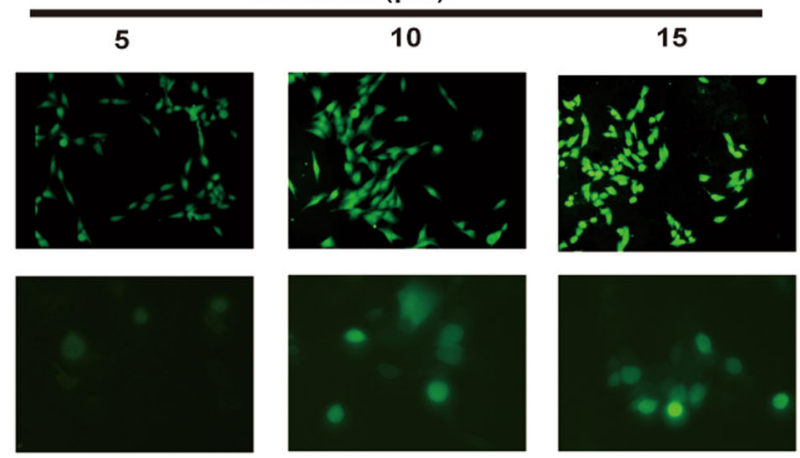

Fig. 2 (See legend on next page.) 
(see figure on previous page)

Fig. 2 Oridonin induced mitochondrial apoptosis in MG-63 and HOS cells. a, b The change of $\Delta \Psi$ in MG-63 and HOS cells was monitored by JC-1 staining and analyzed by flow cytometry. The results are representative of at least three independent experiments and shown as mean \pm SD. ${ }^{* *} P<$ 0.01 compared with control group. c The protein expression of Pro-caspase-3, Cleaved caspase-3, Pro-caspase-9 and Cleaved caspase-9, Bcl-2, Bax were detected by Western blot analysis. $\beta$-actin was used as the loading control. $\mathbf{d}$ Gray scale analysis was performed to determine the relative ratios of Bax/Bcl-2, Cleaved caspase-3/Pro-caspase-3 and Cleaved caspase-9/Pro-caspase-9. The results are shown as means \pm SD from three independent experiments. ${ }^{*} P<0.01$ compared with control group. $\mathbf{e}$, f The mRNA levels of Bax and Bcl-2 in MG-63 and HOS cells were measured by real-time PCR. The results are representative of at least three independent experiments and shown as mean \pm SD. ${ }^{* *} P<0.01$ compared with control group. $\mathbf{g}$, $\mathbf{h}$ The activities of Caspase-9 and Caspase-3 of MG-63 and HOS cells. The results are representative of at least three independent experiments and shown as mean \pm SD. ${ }^{* *} P<0.01$ compared with control group. $\mathbf{i}$ The level of intracellular ROS was measured by flow cytometry. $\mathbf{j}$ The intracellular ROS generation in MG-63 and HOS cells was detected by Fluorescence microscopy. The results are representative of at least three independent experiments and shown as mean $\pm S D$. ${ }^{* *} P<0.01$ compared with control group

activation of NF- $\kappa$ B by activating PPAR- $\gamma$ in MG-63 and HOS cells.

\section{Oridonin induced apoptosis by triggering ROS generation via inhibiting Nrf2 signaling pathway in vitro}

ROS is strictly controlled by an inducible antioxidant program primarily regulated by the transcription factor $\mathrm{Nrf}^{38}$. The evidence has documented that the protein expression of $\mathrm{Nrf} 2$ was significantly lower in normal peritumor tissue than in osteosarcoma tissue ${ }^{27}$. To determine whether the generation of ROS triggered by oridonin was correlated with inhibiting Nrf2 activation, we examined the nuclear translocation of Nrf2 in MG-63 and HOS cells. Western blot analysis showed that oridonin treatment significantly inhibited the nuclear expression of $\mathrm{Nrf} 2$ and raised the cytoplasmic expression of Nrf2 compared with those in the control group (Figs. 4a, b). Oridonin also reversed the nuclear translocation of Nrf2 (Fig. 4c). The downstream of Nrf2 signaling pathway in mammals include NQO1 and $\mathrm{HO}-1^{20}$. Quantitative real-time PCR analysis revealed that NQO1 and $\mathrm{HO}-1$ were downregulated by oridonin in the osteosarcoma cells (Figs. 4d, e). As Fig. 4b shown, oridonin suppressed the protein expression of NQO1 and $\mathrm{HO}-1$ as well.

We further used Nrf2 plasmid to detect whether the effect of oridonin on ROS generation was associated with Nrf2 signaling pathway in vitro. Western blot analysis showed that Nrf2 protein was overexpressed by Nrf2 plasmid (Figs. 5a, b).The inhibitory effect of oridonin on the protein expression and mRNA levels of NQO1 and HO-1 were reversed by Nrf2 plasmid transfection (Figs. 5a-d). Nrf2 plasmid transfection blocked oridonintriggered generation of ROS (Fig. 5e). This suggested that oridonin triggered ROS generation by inhibiting Nrf2 in MG-63 and HOS cells. Moreover, Nrf2 plasmid attenuated oridonin-induced apoptosis in MG-63 and HOS cells (Fig. 5f). Collectively, these results indicated that oridonin induced apoptosis by triggering ROS generation via inhibiting Nrf2 signaling pathway in human osteosarcoma cells.

\section{Oridonin inhibited tumor growth by inducing apoptosis through activating PPAR- $\gamma$ and inhibiting Nrf2 signaling pathway in vivo}

To fully evaluate the anticancer effect of oridonin on osteosarcoma, we established a xenograft model in mice bearing HOS cells in vivo. There were significant differences in tumor volume between treatment groups and control group in the study. Oridonin markedly inhibited tumor growth and decreased the tumor volume (Figs. 6ac). We used TUNEL staining assay to detect the effect of oridonin on the numbers of DNA damage of apoptotic cells in osteosarcoma tumor xenografts. The results depicted a dramatic increase in the TUNEL positive cells in the tumor tissues from oridonin-treated mice compared to the control group (Fig. 6d). Moreover, oridonin dose-dependently increased the ratio of $\mathrm{Bax} / \mathrm{Bcl}-2$ and the cleavage of Caspase- 3 and Caspase- 9 in tumor tissues (Fig. 6e). Oridonin also increased PPAR- $\gamma$ expression and inhibited nuclear translocation of NF- $\mathrm{KB}$ and $\mathrm{Nrf} 2$ in the tumor tissues (Figs. 6f, g). These results were further confirmed by immunohistochemistry staining analysis (Fig. 6h). Our data demonstrated that oridonin inhibited tumor growth by inducing apoptosis through activating PPAR- $\gamma$ and inhibiting Nrf2 signaling pathway in vivo.

Although oridonin inhibited the growth of osteosarcoma in vivo, its possible toxicity must be assessed comprehensively. For the duration of treatment (21 days), the body weight of mice between oridonin-treated and control groups was no significant difference (Fig. 6i). Moreover, no obvious change in major organs can be observed between control and oridonin-treated groups (Fig. 6j). Taken together, our study demonstrated that oridonin inhibited tumor growth with high safety by inducing apoptosis through activating PPAR- $\gamma$ and inhibiting Nrf2 signaling pathway in human osteosarcoma.

\section{Discussion}

Osteosarcoma, the prevailing malignant bone tumor, occurs mainly in children and adolescents. The prognosis of osteosarcoma has been improved dramatically in the last 30 years, however the 5-year survival rate is not 


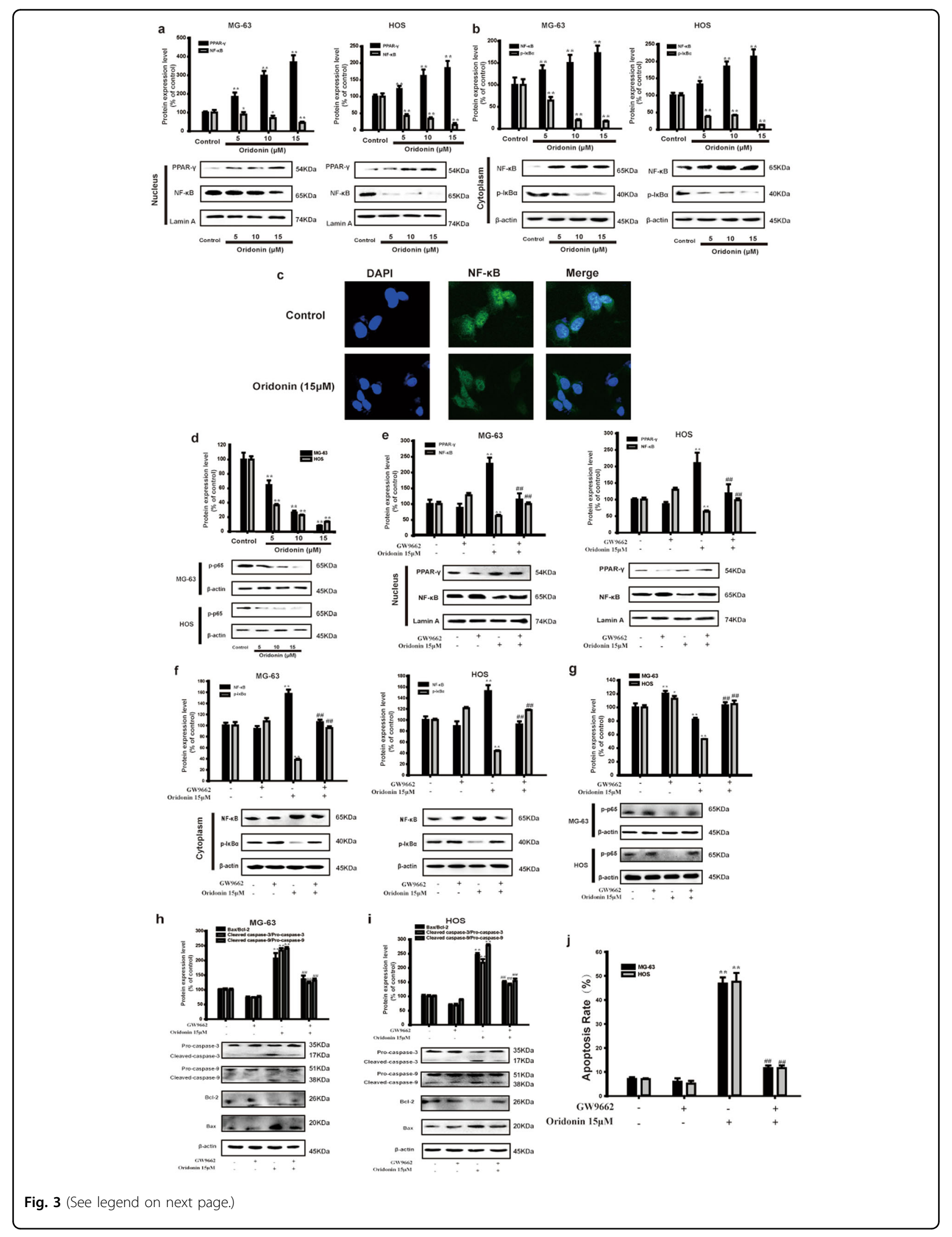


(see figure on previous page)

Fig. 3 Oridonin inhibited NF-KB signaling pathway via activating PPAR- $\gamma$ in vitro. a-d MG-63 and HOS cells were treated with oridonin (5, 10 and 15 $\mu \mathrm{M})$ for $24 \mathrm{~h}$. a Nuclear protein expression of PPAR- $\gamma$ and NF-KB and $\mathbf{b}$ Cytoplasmic protein expression of NF-KB and p-IKBa were detected by Western blot. Lamin $A$ and $\beta$-actin were used as nuclear and cytoplasmic markers, respectively. Gray scale analysis was performed to determine the relative ratios of PPAR- $y, N F-K B$ and $p-I K B a$. The results are shown as means \pm SD from three independent experiments. ${ }^{*} P<0.05$, ${ }^{* *} P<0.01$ compared with control group. c Immunofluorescence was performed to analyze NF-kB p65 nuclear translocation in MG-63 cells. $\mathbf{d}$ The protein expression of p-p65 in MG-63 and HOS cells were determined by Western blot. $\beta$-actin was used as an internal control. Gray scale analysis was performed to determine the relative ratio of $p-p 65$. The results are shown as means \pm SD from three independent experiments. ${ }^{* *} P<0.01$ compared with control group. e-g MG63 and HOS cells were incubated with oridonin $(15 \mu \mathrm{M})$ for $24 \mathrm{~h}$ with pretreatment of GW9662. e Nuclear protein expression of PPAR- $\gamma$ and NF-KB and f Cytoplasmic protein expression of NF-KB and $\mathrm{p}-\mathrm{k}$ Ba were detected by Western blot. Lamin A and $\beta$-actin were used as nuclear and cytoplasmic markers, respectively. Gray scale was performed to determine the relative ratios of PPAR-Y, NF-KB and $p-\mid K B a$. The results are shown as means \pm SD from three independent experiments. ${ }^{*} P<0.01$ compared with control group, ${ }^{\# \#} P<0.01$ compared with $15 \mu \mathrm{M}$ oridonin group. $\mathbf{g}$ The protein expression of p-p65 in MG-63 and HOS cells were determined by Western blot. $\beta$-actin was used as an internal control. Gray scale analysis was performed to determine the relative ratio of $p$-p65. The results are shown as means \pm SD from three independent experiments. ${ }^{*} P<0.05$, ${ }^{* *} P<0.01$ compared with control group; ${ }^{\# \#} P<0.01$ compared with $15 \mu \mathrm{M}$ oridonin group. $\mathbf{h}, \mathbf{i}$ The protein expression of Pro-caspase-3, Cleaved caspase-3, Procaspase- 9 and Cleaved caspase-9, Bcl-2, Bax in MG-63 and HOS cells were detected by Western blot analysis. Gray scale analysis was performed to determine the relative ratios of Bax/Bcl-2, Cleaved caspase-3/Pro-caspase-3 and Cleaved caspase-9/Pro-caspase-9. The results are shown as means \pm SD from three independent experiments. ${ }^{*} P<0.01$ compared with control group; ${ }^{\# \#} P<0.01$ compared with $15 \mu \mathrm{M}$ oridonin group. $\mathbf{j}$ The respective apoptosis rates of different groups were measured by Annexin V/PI staining. The results are representative of at least three independent experiments and shown as mean \pm SD. ${ }^{* *} P<0.01$ compared with control group; ${ }^{\#} P<0.01$ compared with $15 \mu \mathrm{M}$ oridonin group

remarkably increased to date ${ }^{39,40}$. The current drugs for osteosarcoma are limited for the severe toxicities, for instance, doxorubicin with well-documented cardiotoxicity $^{41,42}$. Therefore, it has become a great deal of attention to search for novel more effective but less toxic chemopreventive and anticancer agents. In the current study, we investigated the anti-cancer effect of oridonin on osteosarcoma and unravelled the underlying mechanisms. Our findings demonstrated that oridonin induced apoptosis in osteosarcoma by activating PPAR- $\gamma$ and inhibiting Nrf2 pathway in vitro and in vivo.

Apoptosis is a cellular procedure that is regulated by a variety of executioner and regulatory molecules ${ }^{43}$. The aberrant function of these regulators is extremely essential to the growth of different tumors and confers resistance to anticancer drugs. Both the inactivation of proapoptotic Bcl-2 family proteins and the activation of anti-apoptotic family members are important for the regulation of apoptotic dysregulation in cancer ${ }^{44}$. The anti-apoptotic Bcl-2 family proteins are widely overexpressed in cancer cells to overcome stress signals and thus related to the relaspse, poor prognosis, and resistance to chemotherapy ${ }^{45}$. Therefore, apoptosis has become one of the main molecular targets for drug discovery and development, especially for cancer. Our results revealed that oridonin induced mitochondrial apoptosis by increasing $\mathrm{Bax} / \mathrm{Bcl}-2$ ratio, loss of mitochondrial membranepotential, triggering ROS generation and inducing caspase-9 and caspase-3 cleavage in MG-63 and HOS cells. In vivo study also showed that oridonin induced mitochondrial apoptosis in tumor tissues of xenograft model. These findings suggested that oridonin induced mitochondrial apoptosis in osteosarcoma.

PPAR- $\gamma$ can regulate cell differentiation, growth and apoptosis and is implicated in the several types of cancer pathogenesis and progression ${ }^{46}$. The effect of PPAR- $\gamma$ ligands on cell growth inhibition and apoptosis has been investigated in various cancers ${ }^{47}$. Recent research has showed that knockdown of PPAR- $\gamma$ expression reduces the cleavage of caspase 3 during the early stages of apoptosis ${ }^{48}$. Moreover, studies have documented that PPAR- $\gamma$ activation might be a promising target for osteosarcoma. These properties make PPAR- $\gamma$ activation by natural and synthetic ligands as an attractive strategy for cancer treatment and prevention. Therefore, agents that regulate PPAR- $\gamma$ activation are being actively pursued. In our study, oridonin enhanced the protein expression of PPAR- $\gamma$ in MG-63 and HOS cells. To confirm the effect of oridonin on apoptosis by PPAR- $\gamma$ activation, we used GW9662, a specific inhibitor of PPAR$\gamma$. The results showed that GW9662 reversed the proapoptotic effect of oridonin. It suggested that oridonin induced apoptosis by PPAR- $\gamma$ activation.

Activating PPAR- $\gamma$ displays the anticancer effects through inhibiting the activation of $\mathrm{NF}-\mathrm{KB}^{14,15}$. The downstream target genes of NF- $\mathrm{kB}$ are implicated in the progression of cancer, such as apoptosis, proliferation and migration. Aberrant NF- $\mathrm{kB}$ activation has been observed in numerous human cancers ${ }^{49-52}$. Therefore, NF- $\mathrm{kB}$ has became an interesting therapeutic target for cancer therapy. Moreover, the studies have reported that inhibiting $\mathrm{NF}-\kappa \mathrm{B}$ activation causes apoptosis and cell cycle arrest in osteosarcoma cells as well ${ }^{53,54}$. In the present study we demonstrated that oridonin inhibited the nuclear translocation and activation of NF- $\mathrm{KB}$ in osteosarcoma. Our further results showed that GW9662 and PPAR- $\gamma$ siRNA withdraw the inhibitory effect of oridonin on the nuclear translocation and activation of NF- $\mathrm{KB}$. The pro-apoptotic effect of oridonin was also reversed by GW9662, indicating that oridonin induced apoptosis via inhibiting NF- 

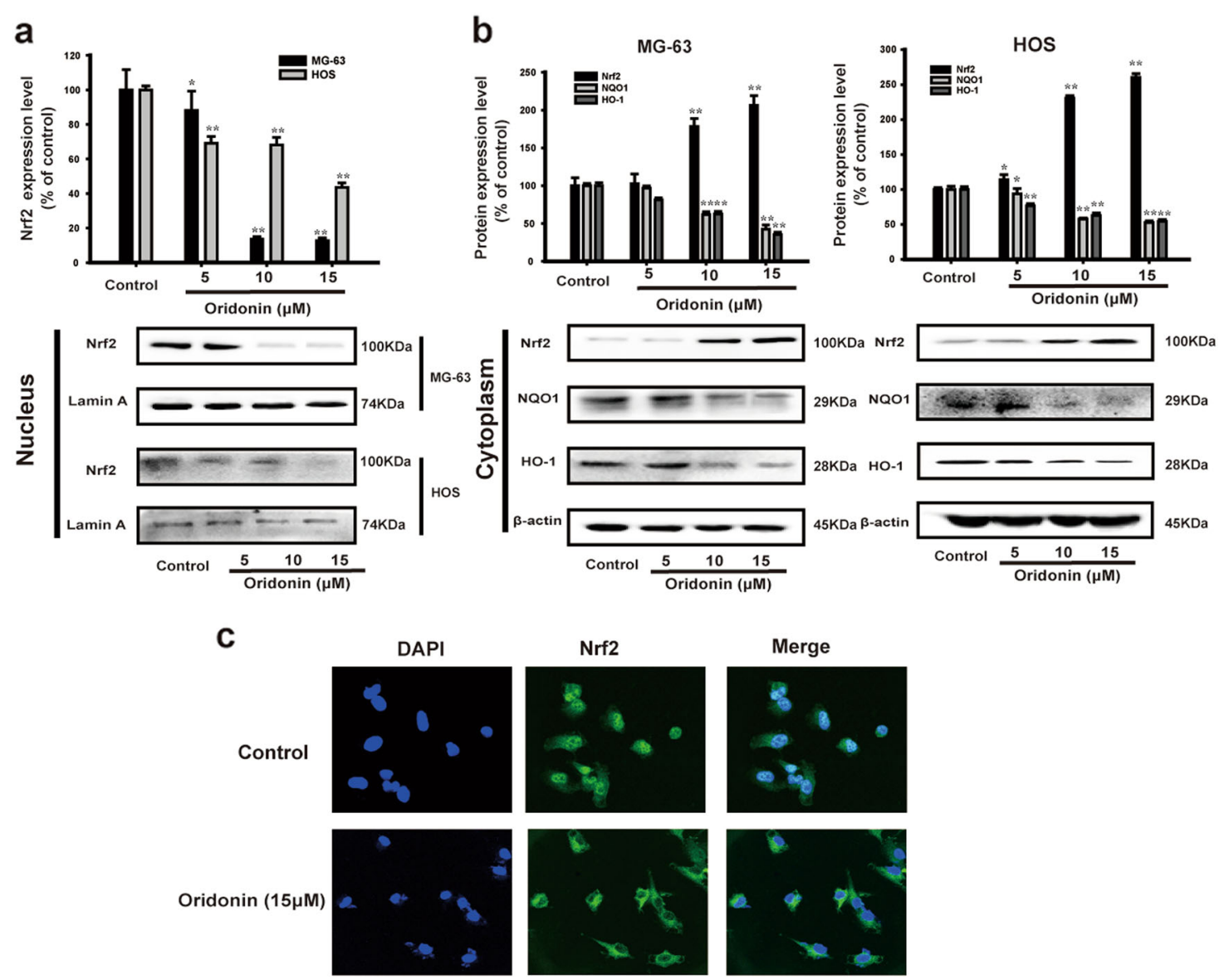

d

MG-63

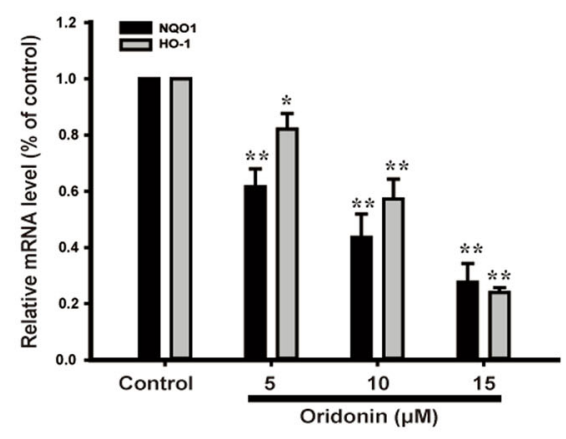

e

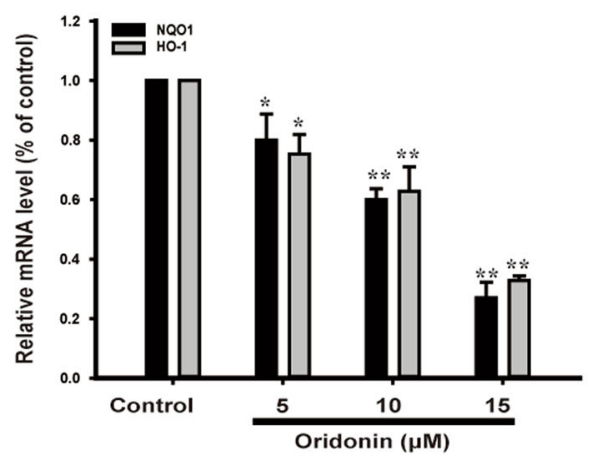

Fig. 4 Oridonin inhibited Nrf2 signaling pathway in vitro. a The nuclear protein expression of Nrf2 in MG-63 and HOS cells were determined by Western blot analysis. Lamin A was used as the loading control. Gray scale analysis was performed to determine the relative ratio of Nrf2. The results are shown as means \pm SD from three independent experiments. ${ }^{*} P<0.05$, ${ }^{* *} P<0.01$ compared with control group. b The cytoplasmic protein expression of Nrf2, NQO1, HO-1 in MG-63 and HOS cells were determined by Western blot analysis. $\beta$-actin was used as the loading control. Gray scale analysis was performed to determine the relative ratios of Nrf2, NQO1 and HO-1. The results are shown as means \pm SD from three independent experiments. ${ }^{*} P<0.05,{ }^{*} P<0.01$ compared with control group. $\mathbf{c}$ Immunofluorescence was performed to analyze Nrf2 nuclear translocation in MG63 cells. $\mathbf{d}$, e The mRNA levels of NQO1, HO-1 in MG-63 and HOS cells were measured by real-time PCR. The results are representative of at least three independent experiments and shown as mean \pm SD. ${ }^{*} P<0.05,{ }^{*} P<0.01$ compared with control group 


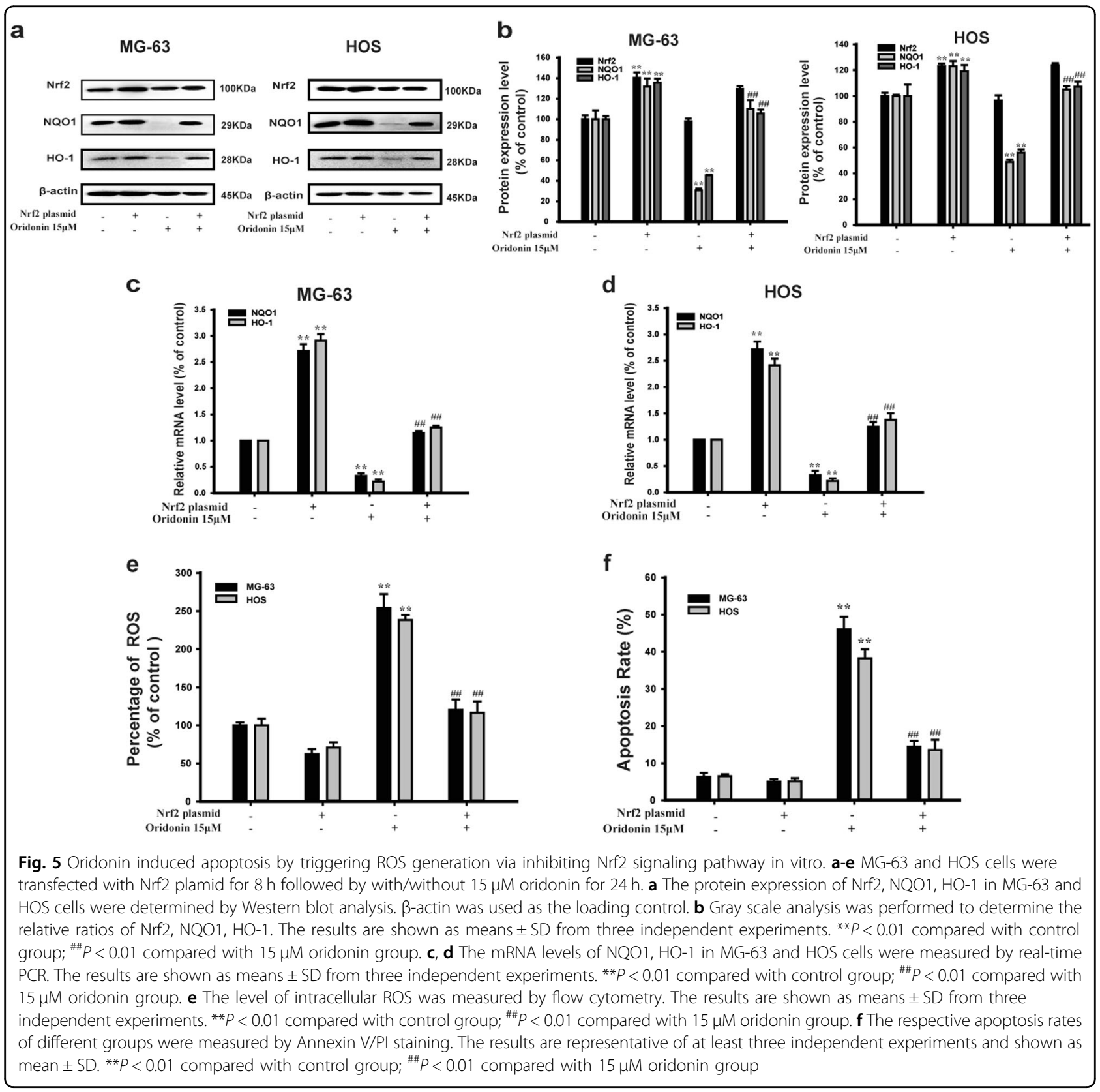

$\kappa \mathrm{B}$ activation by activating PPAR- $\gamma$. Our further in vivo results demonstrated that oridonin induced apoptosis in tumor tissues via inhibiting NF- $\mathrm{\kappa B}$ activation by activating PPAR- $\gamma$.

ROS plays multiple roles in many types of cells, especially important in cell death and signaling ${ }^{55}$. Low levels of ROS act as second messengers in intracellular signaling and are necessary for normal cellular functions, whereas excessive ROS damage cell functions and promote cell death progession ${ }^{56}$. Cancer cells are susceptible to damage by exogenous drug-induced ROS, due to the imbalance of the redox homeostasis ${ }^{57,58}$. In our study, oridonin triggered high level generation of ROS in osteosarcoma cells MG-63 and HOS. It has been reported that ROS levels is mainly controlled by the transcription factor $\mathrm{Nrf}^{38}$. Recent study has documented that Nrf2 was overexpressed in osteosarcoma tissues, and the 5-year survival rate was remarkably higher in patients with negative Nrf2 expression than in those with positive expression $^{27}$. Therefore, inhibiting Nrf2 signaling pathway may be a potential target for the treatment of osteosarcoma. Our results showed that oridonin inhibited the nuclear translocation of Nrf2 and downregulated Nrf2 target genes NQO1 and HO-1 in the osteosarcoma cells. 


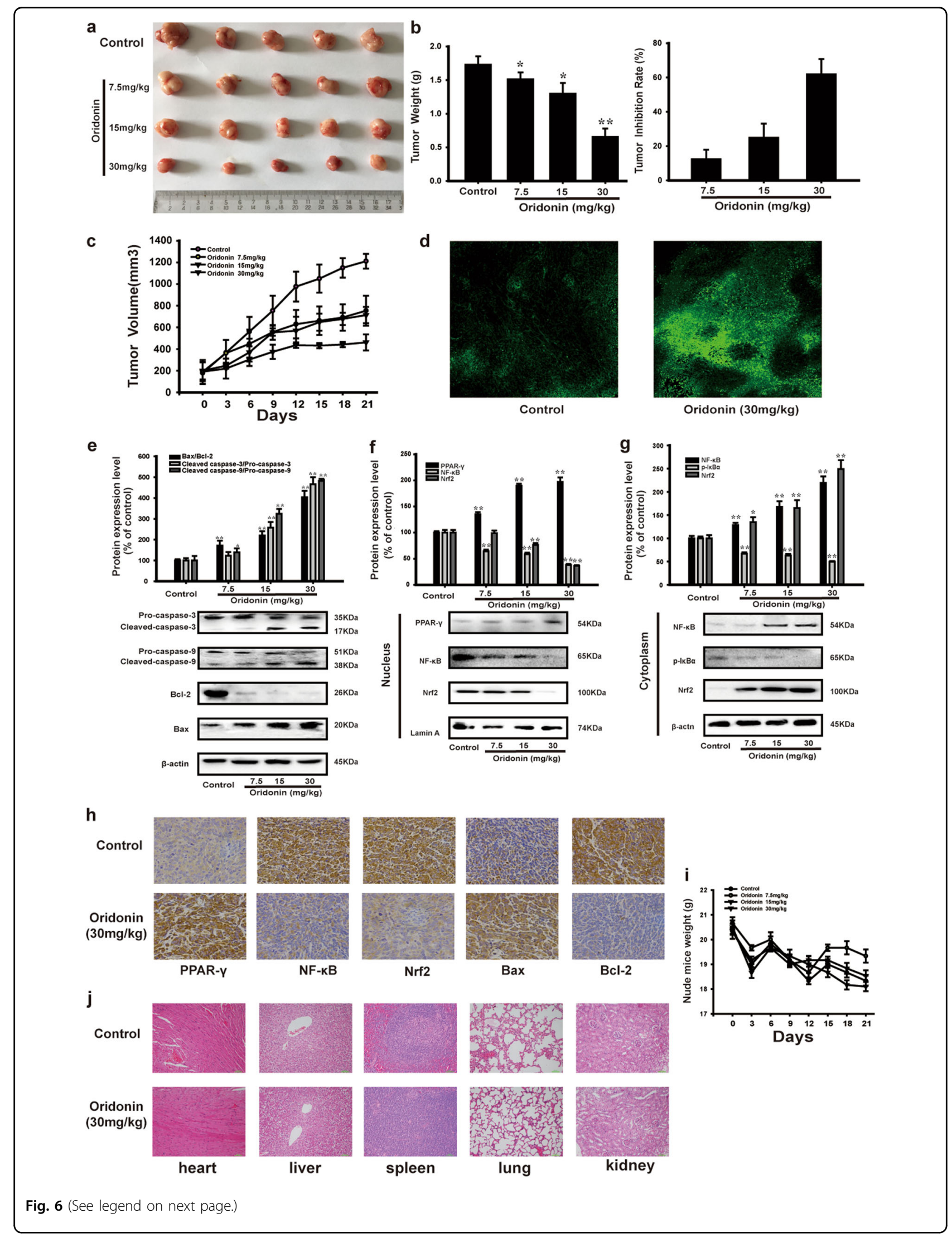




\begin{abstract}
(see figure on previous page)
Fig. 6 Oridonin inhibited tumor growth by inducing apoptosis through activating PPAR- $\gamma$ and inhibiting Nrf2 signaling pathway in vivo. The nude mice bearing HOS osteosarcoma were treated with $30,15,7.5 \mathrm{mg} / \mathrm{kg}$ of oridonin by every 2 days. Control group was treated with normal saline. a The picture of nude mice xenograft tumors was captured after the oridonin treatment for 21 days. b Tumor mass were weighed, and tumor inhibition rate $(\%)=[($ tumor weight of control - tumor weight of treated)/ tumor weight of control $] \times 100 \%$ was statistically analyzed. c Tumor volumes were measured and calculated every 3 days. $\mathbf{d}$ The DNA damage in tumor tissues was determined by TUNEL test $(200 \times)$. e The protein expression of apoptosis-related proteins including Pro-caspase-3, Pro-caspase-9, Cleaved caspase-3, Cleaved caspase-9, Bcl-2 and Bax in tumor tissues were determined by Western blot analysis. $\beta$-actin was used as the loading control. Gray scale analysis was performed to determine the relative ratios of $\mathrm{Bax} / \mathrm{BCl}-2$, Cleaved caspase-3/Pro-caspase-3, Cleaved caspase-9/Pro-caspase-9. The results are shown as means \pm SD from three independent experiments. ${ }^{*} P<0.05,{ }^{* *} P<0.01$ compared with control group. $\mathbf{f}$ The nuclear protein expression of PPAR- $\gamma$, NF-kB and Nrf2 in tumor tissues were determined by Western blot analysis. Lamin A was used as the loading control. Gray scale analysis was performed to determine the relative ratios of PPAR-Y, NF-KB and Nrf2. The results are shown as means \pm SD from three independent experiments. ${ }^{* *} P<0.01$ compared with control group. $\mathbf{g}$ The cytoplasmic protein expression of NF-kB, $\mathrm{p}-\mathrm{IkBa}$ and $\mathrm{Nrf2}$ in tumor tissues were determined by Western blot analysis. $\beta$-actin was used as the loading control. Gray scale analysis was performed to determine the relative ratios of NF-kB, $\mathrm{p}-\mathrm{k} B \mathrm{Ba}$ and $\mathrm{Nrf2}$. The results are shown as means \pm SD from three independent experiments. ${ }^{*} P<0.05,{ }^{*} P<0.01$ compared with control group. $\mathbf{h}$ The protein expression of PPAR- $\gamma, \mathrm{NF}-\mathrm{kB}, \mathrm{Nrf} 2, \mathrm{Bax}$ and BCl-2 in nude mice xenograft tumors were detected by immunohistochemistry. The results are representative of at least three independent experiments. $\mathbf{i}$ Body weight was measured every 3 days. $\mathbf{j}$ The major organs (heart, liver, spleen, lung, and kidney) from treated and control mice was analyzed by H\&E stained (200x)
\end{abstract}

Oridonin suppressed the protein expression of NQO1 and HO-1 as well. The inhibitory effect of oridonin on NQO1 and HO-1 was reversed by Nrf2 plasmid transfection. Nrf2 plasmid transfection also blocked oridonin-triggered generation of ROS. Moreover, oridonin-induced apoptosis was remarkably withdrawn by Nrf2 plasmid transfection. These results showed that oridonin induced apoptosis by triggering ROS generation via inhibiting Nrf2 activation in osteosarcoma. Our in vivo study documented that oridonin inhibited Nrf2 activation in tumor tissues. Furethermore, the standard toxicology studies suggested that oridonin may exert antitumor activity with low levels of toxicity in vivo.

In summary, as a natural compound from Chinese herb medicine, oridonin induced apoptosis and inhibited tumor growth by activating PPAR- $\gamma$ and inhibiting Nrf2 pathway in the osteosarcoma cells and xenograft tumor model (Fig. 7). Thus, these compelling evidences indicated that oridonin may be a potential and effective candidate against human osteosarcoma for its well anticancer efficiency and high safety.

\section{Materials and methods}

\section{Reagents and cell culture}

Oridonin with purity greater than $98 \%$, were purchased from shanghai yuanye Bio-Technology Co., Ltd(Shanghai, China). Modified Eagle Medium (MEM), fetal bovine serum (FBS), benzyl penicillin and streptomycin were purchased from Gibco/BRL (Gaithersburg, MD, USA). 3(4,5-dimethylthiazol-2-yl)-2,5-diphenyltetrazolium bromide (MTT) was obtained from solarbio (Beijing, China).

Primary antibodies against PPAR- $\gamma$, NF- $\mathrm{KB}$ were purchased from Santa Cruz Biotechnology (Santa Cruz, California). Antibodies against Nrf2, NQO1, HO-1, p-p65, p-IкB $\alpha$, Caspase-3, Caspase-9, Bcl-2, Bax, $\beta$-actin, Lamin A were purchased from Cell Signaling Technology (Danvers, MA, USA). The human osteosarcoma cell lines
MG-63, U-2OS, HOS and Saos-2, the human normal cells L02, HEK-293, HUVEC and hFOB 1.19, and human lung cancer cell line A549, human pancreatic carcinoma cell BxPC-3, human colorectal carcinoma cell line HCT-116, human cervical carcinoma cell line Hela, human ovarian cancer cell line SKOV-3, human gastric carcinoma cell line AGS, human leukemia cell line K562 were obtained from Cell Bank of Shanghai Institute of Biochemistry and Cell Biology, Chinese Academy of Sciences. The MG-63 and HOS cells were cultured in Minimum essential medium (Gibco; Thermo Fisher Scientific), while Saos-2, U-2OS and SKOV-3 cells were cultured in McCoy ' 5 A medium (Gibco; Thermo Fisher Scientific), supplemented with $10 \% \mathrm{FBS}$ and $100 \mathrm{U} / \mathrm{ml}$ benzyl penicillin and $100 \mu \mathrm{g} /$ $\mathrm{ml}$ streptomycin. The HEK-293, HUVEC, BxPC-3, HCT116, Hela cells were cultured in Dulbecco's minimum essential medium (Gibco; Thermo Fisher Scientific) with $10 \%$ FBS, and L02, A549, AGS, K562 was cultured in Roswell park memorial institute-1640 (Gibco; Thermo Fisher Scientific) with $10 \%$ FBS, with 100 units/ml penicillin and $100 \mu \mathrm{g} / \mathrm{ml}$ streptomycin. The cells were cultured at $37^{\circ} \mathrm{C}$, hFOB 1.19 were cultured at $33.5^{\circ} \mathrm{C}$, in $5 \% \mathrm{CO}_{2}$.

\section{Cell morphological assessment}

The MG-63 and HOS cells were plated in six-well plates and incubated overnight. After treatment with $0,5,10$, and $15 \mu \mathrm{M}$ oridonin for $24 \mathrm{~h}$, cells were then incubated with 4,6-diamino-2-phenyl indole (DAPI) (Beyotime, China) in the dark for 10 min and washed with phosphate buffer saline (PBS) twice. The cells were observed under a fluorescence microscope (Olympus, Tokyo, Japan) to detect nuclei fragmentation and chromatin condensation.

\section{MTT assay}

The MG-63 and HOS cells were cultured in 96-well plates and incubated overnight. After incubation with oridonin at various concentrations for 24 or $48 \mathrm{~h}, 20 \mu \mathrm{l}$ 


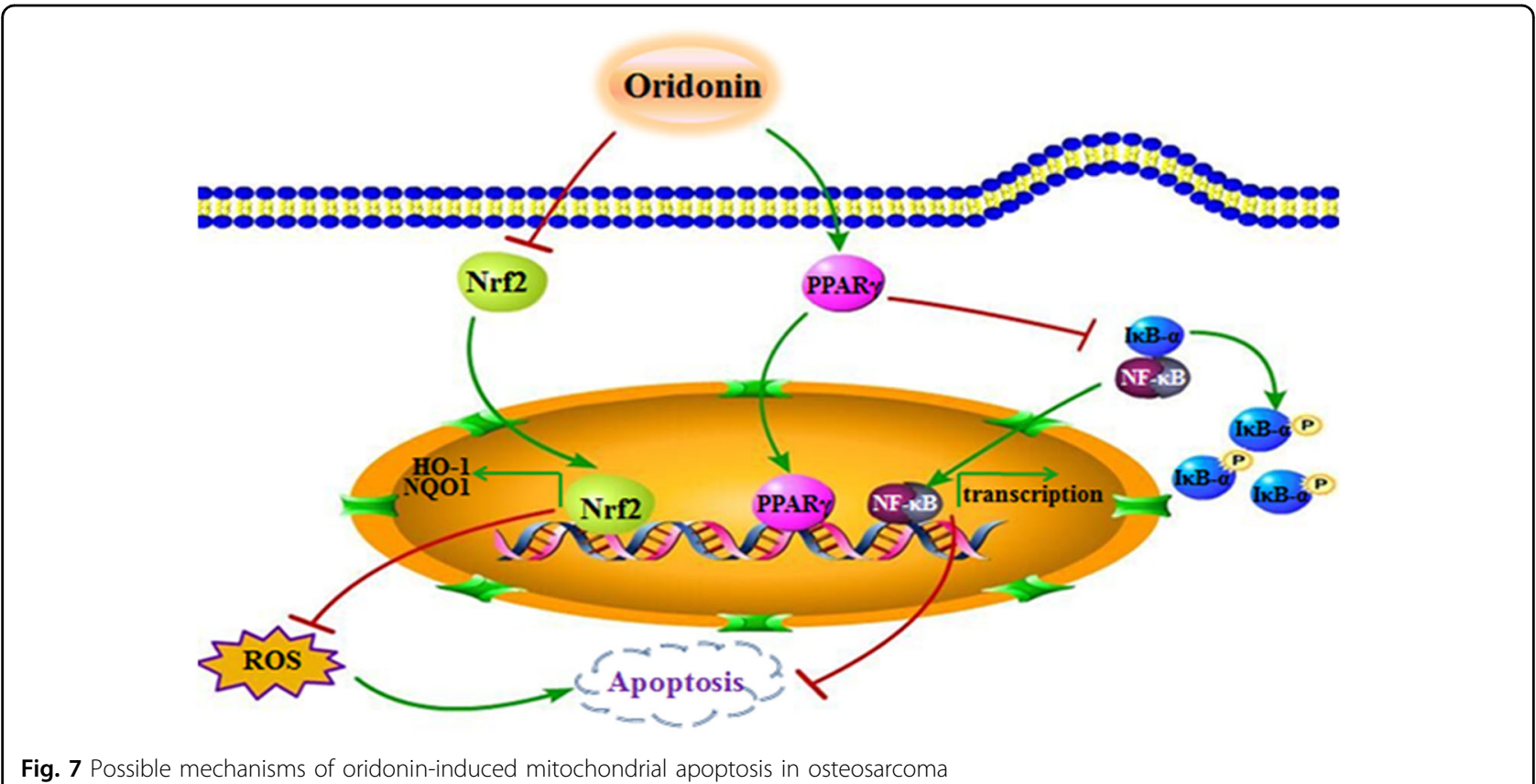

MTT $(5 \mathrm{mg} / \mathrm{mL}$ ) was added to each well, and cells were incubated for another $4 \mathrm{~h}$. The absorbance was measured at $490 \mathrm{~nm}$ with a MR7000 microplate reader (Dynatech, $\mathrm{NV}$, USA). $\mathrm{IC}_{50}$ value was calculated by the software Graphpad Prism. All experiments were performed in triplicate in a parallel manner.

\section{Annexin V/PI staining}

In brief, the MG-63 and HOS cells were seeded in sixwell plates and treated with oridonin at concentrations of $5,10,15 \mu \mathrm{M}$ for $24 \mathrm{~h}$, followed by washing with PBS twice and resuspended in PBS after oridonin exposure, then the cells were stained with the Annexin V/PI Cell Apoptosis Detection Kit (KeyGen, Biotech, Nanjing, China) according to the manufacturer's protocol. The apoptosis rates of the cells were analyzed by flow cytometry (BD Biosciences, San Jose, CA, USA).

\section{Measurement of MMP}

Quantitative changes of MMP was monitored using the MMP-specific fluorescent probe 5, 5', 6, 6'-Tetrachloro-1, 1', 3, 3'-tetraethyl-imidacarbocyanine iodide (JC-1) Apoptosis Detection Kit (KeyGen, Biotech, Nanjing, China). Briefly, oridonin-treated cells were washed with PBS twice, then incubated with JC-1 for $20 \mathrm{~min}$ in the dark at $37{ }^{\circ} \mathrm{C}$. Then the stained cells were washed twice with cold buffer, resuspended and analyzed by a flow cytometer.

\section{Analysis of Caspase- 3 and Caspase- 9 activities}

The Caspase- 3 and Caspase- 9 activities of MG-63 and HOS cells were measured using Caspase Activity Kit (KeyGen Biotech, Nanjing, China) according to the manufacturer's protocol. Samples were measured with Relative Fluorescence Unit (RFU) at $405 \mathrm{~nm}$.

\section{Measurement of ROS}

Generation of intracellular ROS was detected using fluorescent dye 2,7-dichlorofluorescein-diacetate (DCFHDA, Beyotime, China). The MG-63 and HOS cells were exposed to $5,10,15 \mu \mathrm{M}$ oridonin for $24 \mathrm{~h}$ respectively. The cells were collected and resuspended with DCFH-DA(10 $\mu \mathrm{M})$, and incubated for $30 \mathrm{~min}$ in the dark at $37^{\circ} \mathrm{C}$. The level of ROS was determined by using fluorescence microscopy and flow cytometer.

\section{Quantitative real-time PCR analysis}

Total RNA was isolated using the TriPure Solution (Takara Bio, Inc., Otsu, Shiga, Japan) after oridonin treatment, and then generate cDNA templates by reverse transcription reaction using Primescript reverse transcriptase (Takara Bio, Inc.) according to the manufacturer's instructions. Then, the cDNAs were used as templates for determining the expression of related genes by quantitative real-time PCR. Each assay was done in triplicate.

\section{Western blot analysis}

The MG-63 and HOS cells were seeded and incubated with various concentrations of oridonin for $24 \mathrm{~h}$, and then cells were washed with cold PBS and lysed in $300 \mu$ lysis buffer. Protein concentrations were quantified using the BCA assay method with Varioskan spectrofluorometer and spectrophotometer (Thermo, Waltham, MA) at 562 $\mathrm{nm}$. Cell lysates were then subjected to SDS-PAGE and 
transferred onto polyvinylidene difluoride (PVDF) Immobilon-P membrane (Bio-Rad, USA) using a transblot apparatus (Bio-Rad, USA). The membranes were blocked with $5 \%$ skim milk powder at $37^{\circ} \mathrm{C}$ for $1 \mathrm{~h}$ and incubated, each membrane was incubated with antibodies overnight at $4^{\circ} \mathrm{C}$, and then the membranes were incubated with the secondary HRP-conjugated antibody (1:500) (Invitrogen, Carlsbad, USA) for $1 \mathrm{~h}$ at room temperature. Finally, the protein membranes were observed with an Odyssey Scanning System (Li-COR., Lincoln, Nebraska, USA).

\section{Immunofluorescence microscopy}

The MG-63 cells were pretreated with oridinin $(15 \mu \mathrm{M})$ for $24 \mathrm{~h}$. Treated MG-63 cells were collected and cultured onto glass coverslips processed for immunofluorescence. Cells were then fixed, permeabilization and blocked before incubated with primary antibodies (1:50) against NF- $\mathrm{kB}$ and Nrf2 overnight at $4{ }^{\circ} \mathrm{C}$. After washing with PBS, the cells were exposed to FITC-conjugated secondary antibodies (1:100). Then the coverslips were stained with DAPI for $30 \mathrm{~min}$. The images were photographed with an Olympus FV1000 confocal microscope.

\section{Xenograft murine model of HOS cells}

A 35-40 days old Male BALB/c nude mice, weighing 18-22 g, were supplied by Comparative Medicine Centre of Yangzhou University. The animal study was carried out according to National Institutes of Health regulations and approved by the Institutional Animal Care and Use Committee. The mice were maintained in a pathogen-free environment $\left(21 \pm 2{ }^{\circ} \mathrm{C}\right.$ and $45 \pm 10 \%$ humidity) on a $12 \mathrm{~h}$ light and $12 \mathrm{~h}$ dark cycle with food and water supplied freely during the entire experimental. On day $1,5 \times 10^{6}$ HOS cells suspended in $100 \mu$ l PBS were subcutaneously inoculated in the right flank of each nude mice. After $10-12$ days, when tumor sizes reach around $80-150 \mathrm{~mm}^{3}$, then nude mice with similar tumor volume were randomly assigned to four groups (with 6 nude mice/group). Oridonin $(7.5,15,30 \mathrm{mg} / \mathrm{kg})$ groups received intraperitoneal injection of $7.5,15,30 \mathrm{mg} / \mathrm{kg} / 2$ days respectively. The control group was administered saline. Tumor volume (TV) was were measured daily to observe dynamic changes in tumor growth and calculated according to the formula: TV $\left(\mathrm{mm}^{3}\right)=0.5 \times d^{2} \times D$, where $d$ and $D$ are the shortest and the longest diameters, respectively. After 21 days of oridonin administration, when the tumors of control group reached around $1400 \mathrm{~mm}^{3}$, all nude mice were sacrificed.

\section{TUNEL assay}

The terminal deoxynucleotidyl transferase-mediated dUTP nick-end labeling (TUNEL) assay was used to analyze the apoptosis induction in the tissue specimen. It was carried out on Xenograft murine model treated as previously described using an in situ cell death detection kit following the manufacturer's protocol. The slides were photographed under an Olympus FV1000 confocal microscope.

\section{Immunohistochemistry}

The protein expression of PPAR- $\gamma$, NF- $\kappa B$, Nrf2, Bax, $\mathrm{Bcl}-2$ of the tumor tissues was assessed as described in the previous study ${ }^{59}$.

\section{Transfection of PPAR- $\gamma$ siRNA, PPAR- $\gamma$ plasmid and Nrf2 plasmid}

The MG-63 and HOS cells were seeded in six-well plates followed by PPAR- $\gamma$ siRNA, PPAR- $\gamma$ plasmid and Nrf2 plasmid transfections according to the manufacturer's protocol of Lipofectamine 2000 reagent (Invitrogen, Carlsbad, CA, USA) as described previously ${ }^{59}$. After transfections, the MG-63 and HOS cells were exposed to oridonin and harvested for further experiments.

\section{Statistical analysis}

All data were shown as mean \pm standard deviation from at least three independent experiments, each in triplicate samples for individual treatment or dosage. Statistical analyses were performed using ANOVA coupled with a post hoc test. All comparisons are made relative to untreated controls and significance of difference is indicated as ${ }^{*} P<0.05$ and ${ }^{* *} P<0.01$.

\section{Acknowledgements}

This work was supported by the National Natural Science Foundation of China (No. 81373478 and No. 81703556), the Natural Science Foundation of Jiangsu Province (No. BK20171024), Key University Science Research Project of Jiangsu Province (15KJA430006), QingLan Project and Program for Innovative Research Team in University of Jiangsu Province.

\section{Authors' contributions}

$\mathrm{QZ}, \mathrm{YS}$, and BM conceived and designed the experiments; YL performed the experiments, interpreted the data, prepared the figures and wrote the manuscript; JZ analyzed the data and and wrote the manuscript; YL, XJ, and JZ helped to perform experiments; XD helped in writing the manuscript. All authors read and approved the final manuscript.

\section{Competing interests}

The authors declare that they have no competing financial interests.

\section{Publisher's note}

Springer Nature remains neutral with regard to jurisdictional claims in published maps and institutional affiliations.

Supplementary information

The online version of this article (https://doi.org/10.1038/s41419-017-0031-6) contains supplementary material, which is available to authorized users.

Received: 20 June 2017 Revised: 21 September 2017 Accepted: 2 October 2017

Published online: 11 January 2018 


\section{References}

1. Mirabello, L., Troisi, R. J. \& Savage, S. A. International osteosarcoma incidence patterns in children and adolescents, middle ages and elderly persons. Int $J$ Cancer 125, 229-234 (2009).

2. Longhi, A., Errani, C., De Paolis, M., Mercuri, M. \& Bacci, G. Primary bone osteosarcoma in the pediatric age: state of the art. Cancer. Treat. Rev. 32 423-436 (2006)

3. Wafa, H. \& Grimer, R. J. Surgical options and outcomes in bone sarcoma. Expert. Rev. Anticancer. Ther. 6, 239-248 (2006).

4. Ando, K. et al. Current therapeutic strategies and novel approaches in osteosarcoma. Cancers 5, 591-616 (2013).

5. Zhang, $\mathrm{H}$. et al. PEDF and 34-mer inhibit angiogenesis in the heart by inducing tip cells apoptosis via up-regulating PPAR-gamma to increase surface FasL. Apoptosis 21, 60-68 (2016).

6. Wang, T., Xu, J., Yu, X., Yang, R. \& Han, Z. C. Peroxisome proliferator-activated receptor gamma in malignant diseases. Crit. Rev. Oncol. Hematol. 58, 1-14 (2006).

7. Ali, A. A. et al. Rosiglitazone causes bone loss in mice by suppressing osteoblast differentiation and bone formation. Endocrinology. 146, 1226-1235 (2005).

8. Rzonca, S. O., Suva, L. J., Gaddy, D., Montague, D. C. \& Lecka-Czernik, B. Bone is a target for the antidiabetic compound rosiglitazone. Endocrinology. 145 401-406 (2004)

9. Rajkumar, T. \& Yamuna, M. Multiple pathways are involved in drug resistance to doxorubicin in an osteosarcoma cell line. Anticancer Drug 19, 257-265 (2008).

10. Yamaguchi, $\mathrm{K}$. et al. Molecular characterisation of canine nonsteroidal antiinflammatory drug-activated gene (NAG-1). Vet J 175, 89-95 (2008).

11. He, B. C. et al. Synergistic antitumor effect of the activated PPARgamma and retinoid receptors on human osteosarcoma. Clin Cancer Res 16, 2235-2245 (2010).

12. Haydon, R. C., Luu, H. H. \& He, T. C. Osteosarcoma and osteoblastic differentiation: a new perspective on oncogenesis. Clin. Orthop. Relat. Res. 454 237-246 (2007)

13. Haydon, R. C. et al. Nuclear receptor agonists as potential differentiation therapy agents for human osteosarcoma. Clin Cancer Res 8, 1288-1294 (2002).

14. Lee, K. S. et al. Peroxisome proliferator activated receptor-gamma modulates reactive oxygen species generation and activation of nuclear factor-kappaB and hypoxia-inducible factor 1alpha in allergic airway disease of mice. $J$. Allergy. Clin. Immunol. 118, 120-127 (2006).

15. Ichihara, S. et al. Attenuation of cardiac dysfunction by a PPAR-alpha agonist is associated with down-regulation of redox-regulated transcription factors. J. Mol. Cell. Cardiol. 41, 318-329 (2006).

16. Fang, Y. et al. Antitumor activity of NF-kB decoy oligodeoxynucleotides in a prostate cancer cell line. Asian Pacific J Cancer Prevent 12, 2721-2726 (2011).

17. Andela, V. B. et al. Malignant reversion of a human osteosarcoma cell line Saos-2, by inhibition of NFkappaB. Biochem. Biophys. Res. Commun. 297 237-241 (2002)

18. Lee, C. H., Jeon, Y. T., Kim, S. H. \& Song, Y. S. NF-kappaB as a potential molecular target for cancer therapy. Biofactors. 29, 19-35 (2007).

19. Castro-Gamero, A. M. et al. Inhibition of nuclear factor-kappaB by dehydroxymethylepoxyquinomicin induces schedule-dependent chemosensitivity to anticancer drugs and enhances chemoinduced apoptosis in osteosarcoma cells. Anticancer Drug 23, 638-650 (2012).

20. Shen, $C$. et al. Resveratrol pretreatment attenuates injury and promotes proliferation of neural stem cells following oxygen-glucose deprivation/reoxygenation by upregulating the expression of $\mathrm{Nrf} 2, \mathrm{HO}-1$ and $\mathrm{NQO} 1$ in vitro. Mol Med Rep 14, 3646-3654 (2016)

21. Zhang, D. D. Mechanistic studies of the Nrf2-Keap1 signaling pathway. Drug. Metab. Rev. 38, 769-789 (2006).

22. Ping, Z. et al. Sulforaphane protects brains against hypoxic-ischemic injury through induction of Nrf2-dependent phase 2 enzyme. Brain. Res. 1343 178-185 (2010).

23. Sporn, M. B. \& Liby, K. T. NRF2 and cancer: the good, the bad and the importance of context. Nat. Rev. Cancer. 12, 564-571 (2012).

24. Stacy, D. R. et al. Increased expression of nuclear factor E2 p45-related factor 2 (NRF2) in head and neck squamous cell carcinomas. Head. Neck. 28, 813-818 (2006).

25. Shibata, T. et al. Genetic alteration of Keap1 confers constitutive Nrf2 activation and resistance to chemotherapy in gallbladder cancer. Gastroenterology. 135, 1358-1368 (2008). 1368 e1351-1354.
26. Shibata, T. et al. Cancer related mutations in NRF2 impair its recognition by Keap1-Cul3 E3 ligase and promote malignancy. Proc Natl Acad Sci U S A 105 13568-13573 (2008)

27. Zhang, J., Wang, X., Wu, W., Dang, H. \& Wang, B. Expression of the Nrf2 and Keap1 proteins and their clinical significance in osteosarcoma. Biochem. Biophys. Res. Commun. 473, 42-46 (2016).

28. Ren, C. M. et al. Oridonin inhibits the proliferation of human colon cancer cells by upregulating BMP7 to activate p38 MAPK. Oncol. Rep. 35, 2691-2698 (2016).

29. Xu, Z. Z. et al. Reactive oxygen species mediate oridonin-induced apoptosis through DNA damage response and activation of JNK pathway in diffuse large B cell lymphoma. Leuk. Lymphoma. 57, 888-898 (2016).

30. Wang, S. et al. Oridonin induces apoptosis, inhibits migration and invasion on highly-metastatic human breast cancer cells. Am. J. Chin. Med. 41, 177-196 (2013).

31. Li, F. F. et al. Oridonin induces NPM mutant protein translocation and apoptosis in NPM1c+acute myeloid leukemia cells in vitro. Acta. Pharmacol. Sin. 35, 806-813 (2014)

32. Hsieh, T. C., Wijeratne, E. K., Liang, J. Y., Gunatilaka, A. L. \& Wu, J. M. Differentia control of growth, cell cycle progression, and expression of NF-kappaB in human breast cancer cells MCF-7, MCF-10A, and MDA-MB-231 by ponicidin and oridonin, diterpenoids from the chinese herb Rabdosia rubescens. Biochem. Biophys. Res. Commun. 337, 224-231 (2005).

33. Zhou, G. B. et al. Oridonin, a diterpenoid extracted from medicinal herbs, targets AML1-ETO fusion protein and shows potent antitumor activity with low adverse effects on t(8;21) leukemia in vitro and in vivo. Blood. 109 3441-3450 (2007)

34. Liu, C. X. et al. Adenanthin targets peroxiredoxin I and II to induce differentiation of leukemic cells. Nat. Chem. Biol. 8, 486-493 (2012).

35. Shi, X. J. et al. Pro-Apoptotic Effects of JDA-202, a Novel Natural Diterpenoid, on Esophageal Cancer Through Targeting Peroxiredoxin I. Antioxid. Redox. Signal. 27, 73-92 (2017).

36. Owona, B. A. \& Schluesener, H. J. Molecular Insight in the Multifunctional Effects of Oridonin. Drugs R D 15, 233-244 (2015).

37. Das, A., Gopalakrishnan, B., Voss, O. H., Doseff, A. I. \& Villamena, F. A. Inhibition of ROS-induced apoptosis in endothelial cells by nitrone spin traps via induction of phase II enzymes and suppression of mitochondria-dependent pro-apoptotic signaling. Biochem. Pharmacol. 84, 486-497 (2012).

38. DeNicola, G. M. et al. Oncogene-induced Nrf2 transcription promotes ROS detoxification and tumorigenesis. Nature. 475, 106-109 (2011).

39. Sandberg, A. A. Cytogenetics and molecular genetics of bone and soft-tissue tumors. Am. J. Med. Genet. 115, 189-193 (2002).

40. Schwartz, C. L. et al. Multiple drug resistance in osteogenic sarcoma: INT0133 from the Children's Oncology Group. J Clin Oncol 25, 2057-2062 (2007).

41. Horie, T. et al. Acute doxorubicin cardiotoxicity is associated with miR-146ainduced inhibition of the neuregulin-ErbB pathway. Cardiovasc. Res. 87, 656-664 (2010).

42. Meyers, P. A et al. Osteosarcoma: the addition of muramyl tripeptide to chemotherapy improves overall survival--a report from the Children's Oncology Group. J Clin Oncol 26, 633-638 (2008).

43. Mukhopadhyay, S., Panda, P. K., Sinha, N., Das, D. N. \& Bhutia, S. K. Autophagy and apoptosis: where do they meet? Apoptosis 19, 555-566 (2014).

44. Fulda, S. Tumor resistance to apoptosis. Int J Cancer 124, 511-515 (2009).

45. Wuilleme-Toumi, S. et al. Mcl-1 is overexpressed in multiple myeloma and associated with relapse and shorter survival. Leukemia. 19, 1248-1252 (2005).

46. Giaginis, C. et al. Expression of peroxisome proliferator activated receptorgamma (PPAR-gamma) in human non-small cell lung carcinoma: correlation with clinicopathological parameters, proliferation and apoptosis related molecules and patients' survival. Pathol Oncol Res 18, 875-883 (2012).

47. Nagamine, M. et al. PPAR gamma ligand-induced apoptosis through a p53dependent mechanism in human gastric cancer cells. Cancer. Sci. 94, 338-343 (2003).

48. Santha, S., Viswakarma, N., Das, S., Rana, A. \& Rana, B. Tumor Necrosis Factorrelated Apoptosis-inducing Ligand (TRAIL)-Troglitazone-induced Apoptosis in Prostate Cancer Cells Involve AMP-activated Protein Kinase. J. Biol. Chem. 290, 21865-21875 (2015) 
49. Millet, I. et al. Inhibition of NF-kappaB activity and enhancement of apoptosis by the neuropeptide calcitonin gene-related peptide. J. Biol. Chem. 275, 15114-15121 (2000).

50. Chen, F. et al. Phosphorylation of PPARgamma via active ERK1/2 leads to its physical association with p65 and inhibition of NF-kappabeta. J. Cell. Biochem. 90, 732-744 (2003).

51. Matsumoto, G. et al. Targeting of nuclear factor kappaB Pathways by dehydroxymethylepoxyquinomicin, a novel inhibitor of breast carcinomas: antitumor and antiangiogenic potential in vivo. Clin Cancer Res 11, 1287-1293 (2005).

52. Kikuchi, E. et al. Suppression of hormone-refractory prostate cancer by a nove nuclear factor kappaB inhibitor in nude mice. Cancer. Res. 63, 107-110 (2003)

53. Hafeez, B. B. et al. Green tea polyphenols-induced apoptosis in human osteosarcoma SAOS-2 cells involves a caspase-dependent mechanism with downregulation of nuclear factor-kappaB. Toxicol. Appl. Pharmacol. 216, 11-19 (2006).
54. Tanaka, H. et al. Calyculin A induces apoptosis and stimulates phosphorylation of p65NF-kappaB in human osteoblastic osteosarcoma MG63 cells. Int. J. Oncol. 31, 389-396 (2007).

55. Thannickal, V. J. \& Fanburg, B. L. Reactive oxygen species in cell signaling. Am J. Physiol. Lung. Cell. Mol. Physiol. 279, L1005-L1028 (2000).

56. Circu, M. L. \& Aw, T. Y. Reactive oxygen species, cellular redox systems, and apoptosis. Free. Radic. Biol. Med. 48, 749-762 (2010).

57. Trachootham, D., Alexandre, J. \& Huang, P. Targeting cancer cells by ROSmediated mechanisms: a radical therapeutic approach? Nat. Rev. Drug. Discov. 8, 579-591 (2009).

58. Kawanishi, S., Hiraku, Y., Pinlaor, S. \& Ma, N. Oxidative and nitrative DNA damage in animals and patients with inflammatory diseases in relation to inflammation-related carcinogenesis. Biol. Chem. 387, 365-372 (2006).

59. Sun, Y. et al. Wogonoside protects against dextran sulfate sodium-induced experimental colitis in mice by inhibiting NF-kappaB and NLRP3 inflammasome activation. Biochem. Pharmacol. 94, 142-154 (2015). 